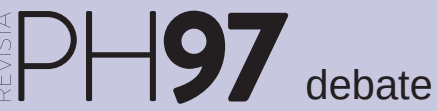

a debate El papel del patrimonio en las nuevas políticas para la cultura, la ciudad y el territorio:

las agendas urbanas como marco de oportunidad

| coordinan Blanca del Espino Hidalgo, Rafael Merinero Rodríguez

\title{
Patrimonio arqueológico y desarrollo local en La Rinconada (Sevilla)
}

\author{
Francisco José García Fernández | Universidad de Sevilla \\ Maribel Rodríguez Achútegui | Museo Arqueológico y Paleontológico de La Rinconada \\ URL de la contribución <http://www.iaph.es/revistaph/index.php/revistaph/article/view/4396>
}

Esta reflexión surge a raíz de la puesta en marcha de un proyecto general de investigación que tiene por objeto el estudio arqueológico y la activación patrimonial de Cerro Macareno, un yacimiento situado en el municipio de La Rinconada y uno de los principales recursos culturales de la localidad.

El interés de este caso reside, por una parte, en su potencial para conocer la introducción de las formas de vida urbana en el valle del Guadalquivir durante la Edad del Hierro, desde los inicios de la colonización fenicia hasta la eclosión de la cultura turdetana y los primeros compases de la romanización, condensada en sus más de $7 \mathrm{~m}$ de depósitos arqueológicos. Pero, sobre todo, es relevante porque responde a un modelo de investigación aplicada que aspira a transformar este recurso, a través del conocimiento y la innovación, en un motor de desarrollo local bajo las claves de la sostenibilidad urbana y territorial.

La Rinconada no se caracteriza por albergar un patrimonio emergente especialmente atrayente, ya que la mayor parte de su riqueza reside en los bienes arqueológicos de su término municipal, que en muchos casos son difíciles de visibilizar e interpretar. Entre la amplia nómina de yacimientos registrados sobresalen sobre todo las antiguas graveras, que albergan un rico patrimonio paleontológico y prehistórico, único en la región, y el propio Cerro Macareno, cuya historia ha estado también marcada por la explotación de una cantera de áridos. Los estudios llevados a cabo en los años setenta con motivo de su descubrimiento pusieron de relieve su enorme valor científico y garantizaron su protección, mediante la paralización de las actividades extractivas, aunque nunca se llegó a materializar el expediente de declara- ción de utilidad pública de los terrenos, que se puso en marcha los últimos años de la dictadura, ni tuvieron continuidad las excavaciones emprendidas.

A pesar de ello, el interés por hacer este patrimonio más accesible y comprensible a la ciudadanía ha dado lugar a iniciativas singulares y de gran calado social que han acabado integrándose en las políticas municipales y convirtiéndose en uno de los principales ejes del planeamiento estratégico. En especial cabe destacar la labor de Francisco Sousa, un profesor de instituto que decidió impulsar a mediados de la década de los 80 del siglo pasado un proyecto para que su alumnado pudiera acercarse al mundo de las ciencias arqueológicas y paleontológicas de forma práctica. Para ello creó un grupo de arqueología y consiguió que toda una generación de alumnos trabajara activamente para la creación de una colección arqueológica. Así pues, los orígenes del Museo Arqueológico y Paleontológico de La Rinconada, fruto de esta labor, están más ligados a la educación que a la investigación científica, lo que ha marcado profundamente el carácter social y educativo de esta institución, cuyos fondos son una colección formada directamente por la ciudadanía.

Desde que abriera sus puertas en 2009, el museo ha ido encontrando poco a poco su lugar en el territorio. En estos primeros diez años de andadura se ha configurado como la institución patrimonial del municipio, de forma que, más allá de los propios contenidos de la colección, el museo ha impulsado programas y actividades de dinamización más amplios y transversales relacionados con la gastronomía, la identidad, la memoria democrática, el patrimonio industrial, etc. También aspira a ser un recurso educativo para La Rinconada, ofertando un 
a debate El papel del patrimonio en las nuevas políticas para la cultura, la ciudad y el territorio: las agendas urbanas como marco de oportunidad

| coordinan Blanca del Espino Hidalgo, Rafael Merinero Rodríguez

catálogo de actividades, adaptadas a todos los curricula escolares, desde la educación infantil hasta el bachillerato, destacando sobre todo las actividades dirigidas a que los jóvenes de la localidad, que son los que recogen directamente el testigo del pasado, tengan un proceso de inmersión en el patrimonio a través de metodologías participativas.

La aprobación el pasado 2016 de la Estrategia de Desarrollo Urbano Sostenible e Integrado (EDUSI) Rinconada, Ciudad Única 2022 se ha convertido en una oportunidad para coordinar e implementar estas iniciativas con una visión estratégica, a escala local, pero también metropolitana. De hecho, la Línea de Actuación 7: Regeneración del patrimonio histórico y cultural prevé explícitamente "desarrollar herramientas de planificación y actuar en la mejora y rehabilitación de las áreas del municipio que son patrimonio histórico y cultural, mejorando su estado de conservación y promoviendo su uso y disfrute por la ciudadanía de La Rinconada y visitantes", en estrecha relación con la Línea 6: Creación de nuevos espacios verdes y regeneración del entorno natural, y la Línea 8: Regeneración y mejora del paisaje urbano. Ello permite dar un salto del planeamiento a la gestión integrada de los recursos, mucho más eficaz en términos de gobernanza, situando a las necesidades de la ciudadanía en el epicentro de los proyectos, tal como recoge el Plan Estratégico 2018-2022.

Así pues, a pesar de que el PGOU de La Rinconada se ha mostrado sensible con la protección de su patrimonio histórico y cultural, especialmente con Cerro Macareno, donde se prevé la creación de un parque urbano y la puesta en valor del yacimiento arqueológico y del arroyo Almonázar, a lo que hay que sumar la promoción del expediente de catalogación de Cerro Macareno como bien de interés cultural bajo la figura de zona arqueológica, la EDUSI permite ir más allá, garantizando la adecuada integración de este espacio y su transformación en un producto cultural mediante actuaciones y programas que permitan su aprovechamiento social. En este contexto, el proyecto Cerro Macareno (La Rinconada, Sevilla): arqueología y patrimonio en

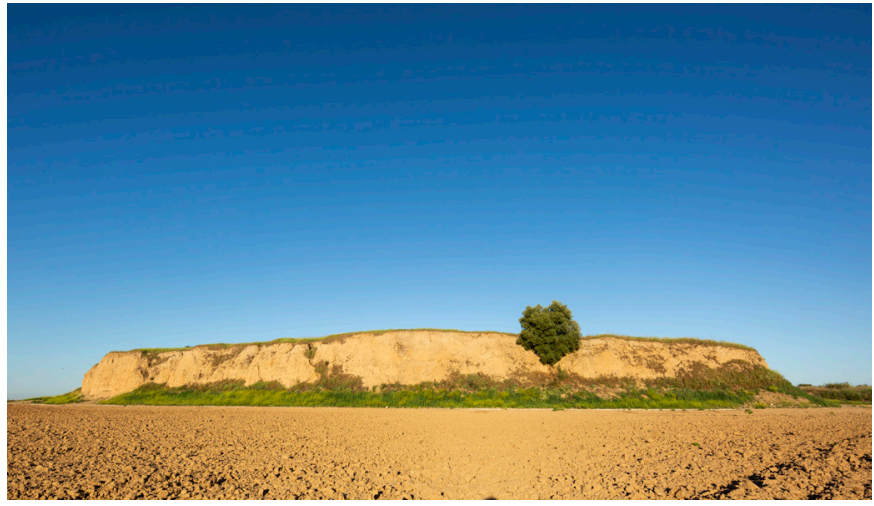

Cerro Macareno, vista de la elevación oriental desde el noreste | foto Anna Elías Manén

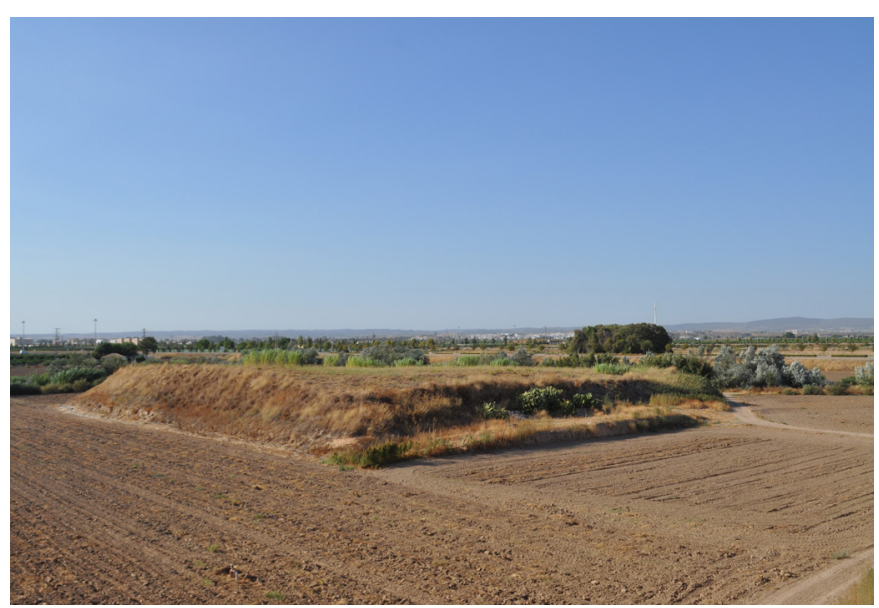

Cerro Macareno, vista de la elevación occidental desde el sureste | foto Francisco J. García Fernández

la vega del Guadalquivir, fruto de la estrecha colaboración entre la Universidad de Sevilla y el Ayuntamiento de La Rinconada, plantea entre sus líneas de actuación no solo el estudio arqueológico del yacimiento, sino también el análisis experimental de los procedimientos de conservación más adecuados para el tipo de restos que alberga, el examen de las fórmulas más adecuadas de integración urbanística de la parcela y la propuesta de estrategias orientadas a la difusión de los resultados de la investigación, la puesta en valor y la musealización de los restos. Estas últimas se llevan a cabo bajo la coordinación del Museo Arqueológico y Paleontológico, que se convierte en la correa de transmisión entre el proyecto 
a debate El papel del patrimonio en las nuevas políticas para la cultura, la ciudad y el territorio: las agendas urbanas como marco de oportunidad

| coordinan Blanca del Espino Hidalgo, Rafael Merinero Rodríguez

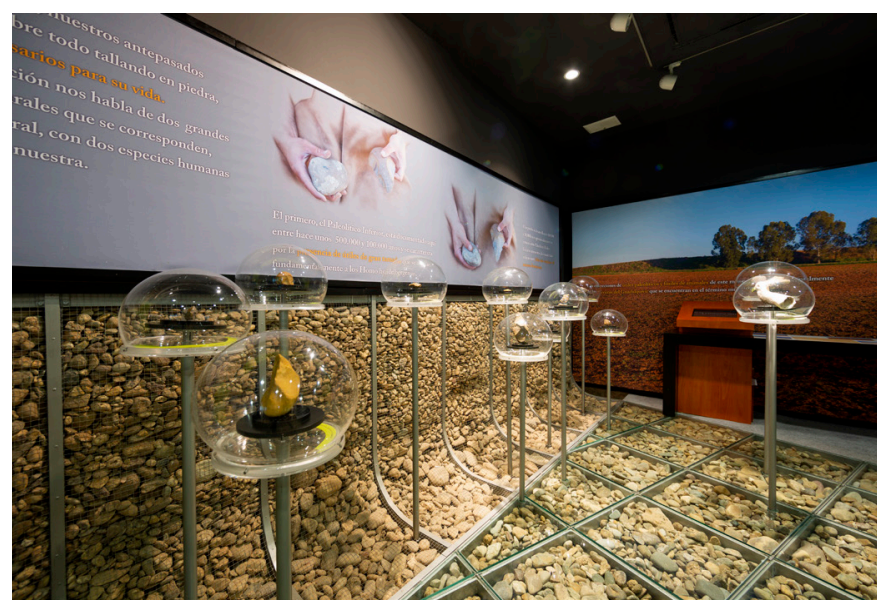

Museo Arqueológico y Paleontológico de La Rinconada, sala Paleolítico | foto Anna Elías Manén

y la ciudadanía. Al mismo tiempo, esta institución debe afrontar el reto de integrar en el discurso museográfico los nuevos materiales, datos y aspectos históricos desvelados por la investigación, así como las necesidades de conservación, promoción de la investigación y difusión, de acuerdo con las funciones que le atribuye la Ley de Museos y Colecciones Museográficas de Andalucía.

En definitiva, la EDUSI y, sobre todo, la implementación de la Agenda Urbana 2030 en La Rinconada, ofrece un escenario propicio para otorgar al patrimonio arqueológico un papel protagonista en las nuevas políticas culturales del municipio, así como para desarrollar actuaciones innovadoras y eficientes, que garanticen la transferencia del conocimiento al tejido social y contribuyan al desarrollo local, con una adecuada gestión de los recursos y un mínimo impacto ambiental. No cabe duda de que Cerro Macareno ocupará un lugar central en este proceso, por su singularidad y enorme potencial científico y patrimonial, por lo que la planificación y coordinación de las distintas líneas de trabajo y actores implicados de cara a traducir estas directrices en propuestas concretas será la principal tarea a acometer en el futuro. 